\title{
Moisture state variety in poplar lumber with moisture content above fibre saturation point during hot-press drying
}

\author{
Junfeng Hou ${ }^{1,2} \cdot$ Songlin $\mathrm{Yi}^{2} \cdot$ Yongdong Zhou ${ }^{1} \cdot \operatorname{Bin} \mathrm{Pan}^{1}$
}

Received: 11 April 2018 / Accepted: 12 August 2018 / Published online: 19 September 2018

(c) The Japan Wood Research Society 2018

\begin{abstract}
Hot-press drying has gained attention due to its excellent drying rate and surface strengthening effect. The moisture state in poplar lumber (Populus tomentosa) with moisture content (MC) above fibre saturation point (FSP) was analyzed during hot-press drying. The effect of heating platens' temperature on the temperature and pressure inside poplar lumber was investigated. The moisture state changes inside the poplar lumber during hot-press drying were further analysed in accordance with the measured pressure and theoretical pressure calculated with the measured temperature inside poplar lumber. Results were as follow: When the heating platens' temperature increased from 120 to $140{ }^{\circ} \mathrm{C}$, the maximum values of temperature and pressure also increased by 14.5 and $26.2 \%$, respectively. However, a delay occurred between the maximum values of pressure and temperature. The moisture at the center layer of poplar lumber with MC above FSP was in liquid state, i.e. unsaturated water under overpressure condition in hot-press drying process. Flashing occurred to the unsaturated water in poplar lumber during the opening period of heating platens and resulted in the decrease in MC. This phenomenon is the main moisture transfer mode in wood hot-press drying process with MC above FSP.
\end{abstract}

Keywords Popluous tomentosa $\cdot$ Hot-press drying $\cdot$ Temperature $\cdot$ Pressure $\cdot$ Moisture state

\section{Introduction}

Hot-press drying shows advantage in improving drying rate and surface strengthening of wood [1]. The hot-press drying characteristics of wood have been studied [2-5]. And most of these investigations focused on the effects of drying on drying time [6], drying quality [7], physical-mechanical properties [8] and microstructure [9] of hot-press drying wood. The results showed that the drying rate increased, and

Yongdong Zhou

zhouyd@caf.ac.cn

Junfeng Hou

houjunfeng2015@163.com

Songlin Yi

ysonglin@bjfu.edu.cn

Bin Pan

panbin@caf.ac.cn

1 Research Institute of Wood Industry, Chinese Academy of Forestry, Beijing 100091, People's Republic of China

2 College of Material Science and Technology, Beijing Forestry University, Beijing 10083, People's Republic of China the drying quality [10], and physical-mechanical properties were improved [11].

Theoretical hypotheses proposed that the driving force for moisture transfer is vapour pressure [12-14]. A mass transfer model, which was established based on the vapour pressure gradient in Masson's pine (Pinus massoniana) lumber with $\mathrm{MC}$ above FSP, can reflect the moisture migration regularity at a temperature range from 100 to $110^{\circ} \mathrm{C}$ in high-temperature drying process [15]. The vapour pressure was also applied to the establishment and experimental verification of mathematical model, which describes the temperature and $\mathrm{MC}$ changes in microwave-vacuum drying process [16]. However, moisture in wood is changed to vapour once its temperature reaches $100{ }^{\circ} \mathrm{C}$ in drying; the corresponding vapour pressure is theoretically calculated based on ideal gas equation and not experimentally measured in aforementioned studies [12-16]. Additionally, experimental investigation of vapour pressure inside Masson pine lumber indicated that the internal vapour pressure difference, which was formed inside the lumber, is the driving force of moisture moving in microwave drying process [17]. The internal temperature and relative pressure were also experimentally investigated and applied to TransPore and 
Front 2D mathematical model to simulate the vacuum drying of wood with far IR radiation heating [18, 19]. Both models well described drying at a reduced external pressure. Thus, vapour temperature and pressure plays an important role in heat and mass transfer analysis in wood drying process.

The heat and mass transfer regularity in wood during hot-press drying have been investigated. Most of these studies focused on establishing heat and mass transfer models using temperature and moisture gradient as driving forces during hot-press drying [20, 21]. The basic hypothesis in modeling about water evaporating inside wood is that the water phase is converted to vapour once the temperature was above $100{ }^{\circ} \mathrm{C}$. During the simulation of heat and mass transfer model, the corresponding vapour pressure was theoretically calculated according to ideal gas equation, but was not experimentally measured or verified. However, the moisture state was determined by temperature and pressure in accordance with thermodynamic principle. Given that wood MC is above FSP, the water inside wood during hotpress drying may not change to vapour immediately when the temperature increases to $100{ }^{\circ} \mathrm{C}$ under a pressure above atmospheric pressure. Therefore, the variation of moisture state in wood under the combined effect of temperature and pressure during hot-press drying should be analysed. Horizontal pressure and temperature distribution responses to oriented-strand board (OSB) flake alignment were successfully investigated at $180^{\circ} \mathrm{C}$ during hot pressing [22]. This method is suitable to simultaneously measure the pressure and temperature in the same point inside wood. Additionally, investigations are lacking on the moisture state by analysing temperature and pressure during wood drying.

In this paper, the moisture state changes inside poplar lumber with MC above FSP in hot-press drying process were analysed in accordance with the measured pressure $\left(P_{\mathrm{M}}\right)$ and temperature $\left(T_{\mathrm{M}}\right)$ inside lumber. This study aimed to determine the effect of heating platens' temperature $\left(T_{\mathrm{P}}\right)$ on the moisture state in lumber with MC above FSP during hot-press drying. The results will provide a foundation for the further research on mechanism and model during hotpress drying.

\section{Materials and methods}

\section{Experimental materials}

Poplar (Populus tomentosa) logs were collected from a 15-year-old plantation in Shandong Province, China. The diameter of log was in a range of 20 to $45 \mathrm{~cm}$ at the breast height. The basic density was $0.439 \pm 0.015 \mathrm{~g} \mathrm{~cm}^{-3}$. Before experiments, the log was sawn to lumber with the following dimensions: $400 \times 120 \times 25 \mathrm{~mm}$ (longitudinal $\times$ tangential $\times$ radial). The initial MC of specimen ranged from 40 to $60 \%$.

\section{Hot-press drying of poplar lumber}

The hot-press drying of poplar lumber was performed with a laboratory type single-opening hot press (Shanghai Artificial Board Machinery Factory, Shanghai, China, Fig. 1a), and the dimensions of heating platen is $500 \times 500 \mathrm{~mm}$ (length $\times$ width). Poplar lumber specimens were sealed on both sides and ends with high-temperature-resistant epoxy resin (DY-E802, Hunan Baxiongdi New Material Co., Ltd, Hunan Province, China) and a 0.2-mm-thick aluminum foil (Guangzhou High Strength Plastic Packaging Products

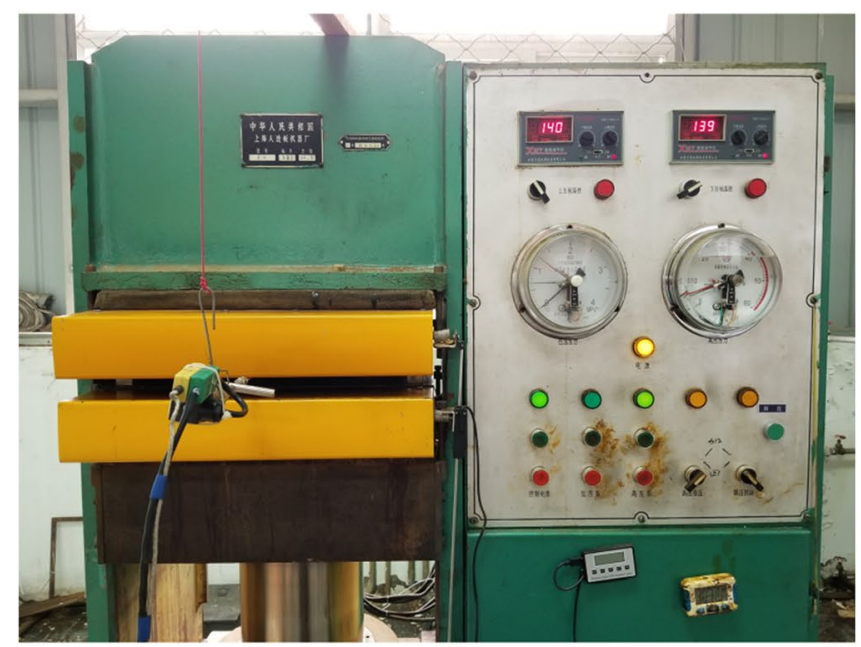

(a) The single-opening hot-press

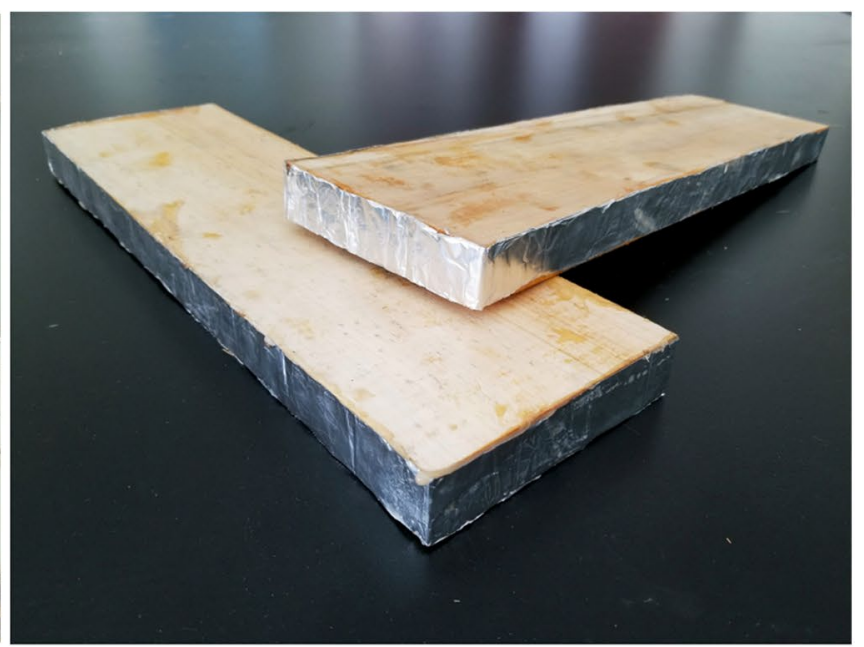

(b) The placed specimen covered with aluminum foil

Fig. 1 The hot-press dryer (a) and the poplar lumber specimen (b) 
Factory, Guangdong Province, China) to ensure that moisture was only transferred in the thickness direction (Radial direction) inside lumber as shown in Fig. 1b. The poplar lumber specimen was placed in hot press with $T_{\mathrm{P}}$ as 120 , 130 and $140{ }^{\circ} \mathrm{C}$. The heating platen's closing duration was $30 \mathrm{~min}$ and opening time was $2.4 \mathrm{~min}$, during which the moisture can be discharged quickly before the temperature and pressure reached stable value. The compression ratio of lumber was set to $4 \%$ to assure the close contact between lumber and heating platens in drying process. A thickness gauge was applied to maintain the required thickness of lumber during hot-press drying. The MC distribution of lumber was investigated in accordance with GB/T 6491 standard [23]. Cutting method of three MC distribution pieces from a tested poplar lumber specimen is shown in Fig. 2. Three MC distribution pieces were measured for each tested poplar lumber specimen (Fig. 2). Three replicate specimens for MC distributions were measured for each drying condition, and the average MC values of nine pieces were used for the final analysis.

\section{Temperature and pressure inside poplar lumber during drying}

The temperature and pressure in poplar lumber were monitored using an integrated temperature-pressure probe
(Shenyang Xinyi Automation equipment Co., Ltd, Liaoning Province, China), which was embedded in the geometric center of lumber as illustrated in Fig. 3. A pressure transmitter and K-type thermocouple with 0.5-mm-diameter was included in this probe (Fig. 3). The monitoring range of pressure transmitter is 0 to $500 \mathrm{kPa}$, and its temperature monitoring range is 0 to $500{ }^{\circ} \mathrm{C}$. A 2-mm-diameter-hole was drilled into the geometric center of lumber (Fig. 4a), and its depth was $60 \mathrm{~mm}$ in tangential direction (Fig. 4b). Temperature $\left(T_{\mathrm{M}}\right)$ and pressure $\left(P_{\mathrm{M}}\right)$ at the center layer of lumber were recorded with a data logger (SIN-R6000C, Hangzhou Sinomeasure Automation Technology Co., Ltd, Zhejiang Province, China) with a time interval of $6 \mathrm{~s}$. Three replicate specimens for the pressure and temperature were measured, and the average temperature and pressure values were used for the final analysis.

\section{Results and discussion}

\section{Temperature behaviors}

The temperature $\left(T_{\mathrm{M}}\right)$ behaviors in poplar lumber under different $T_{\mathrm{P}}$ values during hot-press drying are shown in Fig. 5 . The results showed that $T_{\mathrm{M}}$ rapidly increased after the closing of heating platens, and the maximum temperature was

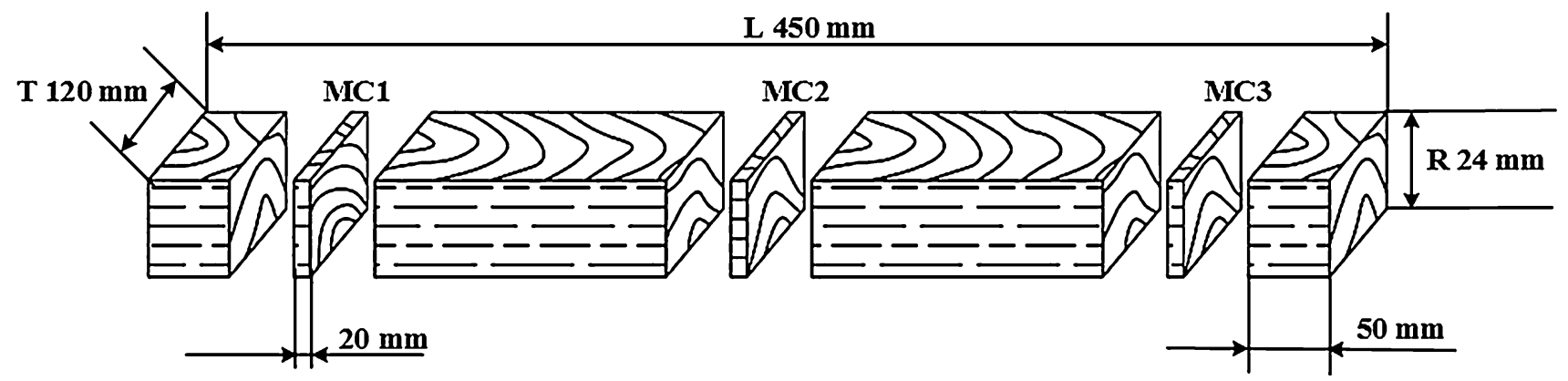

Fig. 2 Cutting method of three moisture content (MC) distribution pieces from a tested poplar lumber specimen

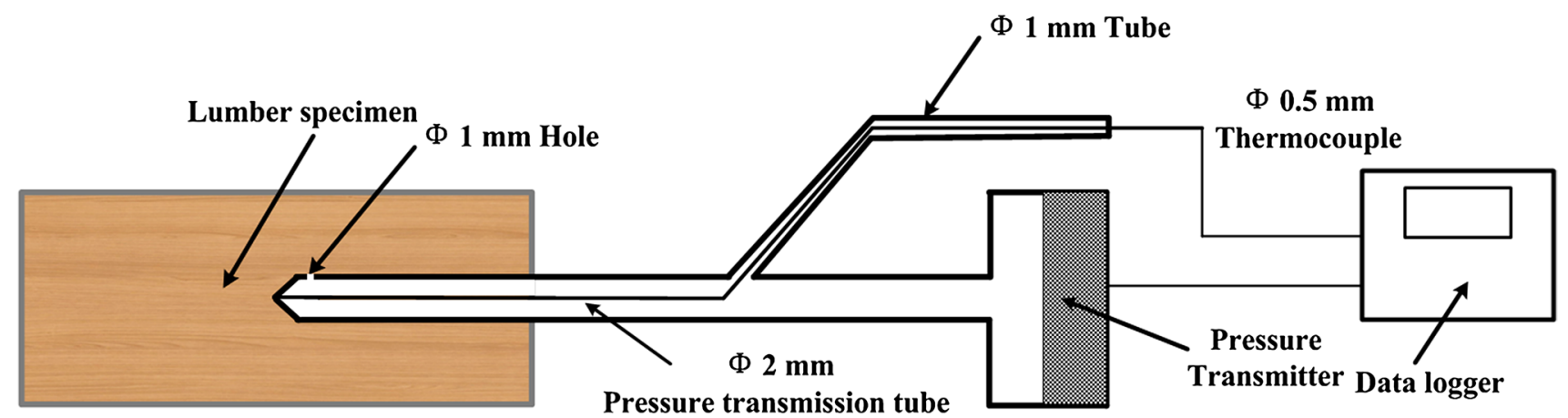

Fig. 3 Diagram of integrated temperature-pressure probe embedded in lumber 
Fig. 4 Location of the integrated temperature-pressure probe in poplar lumber

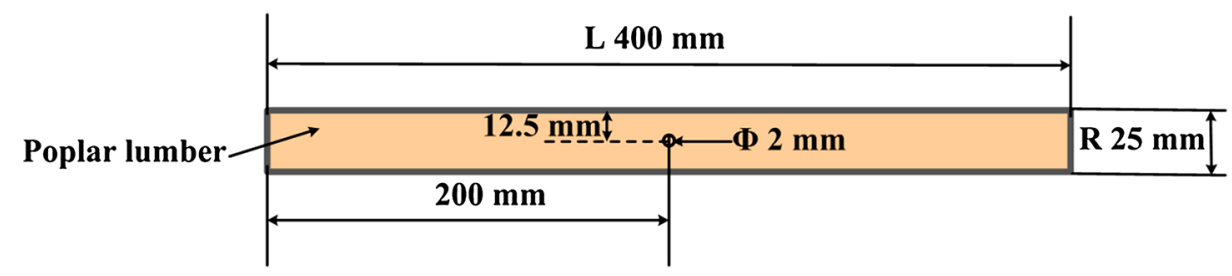

(a) Front view

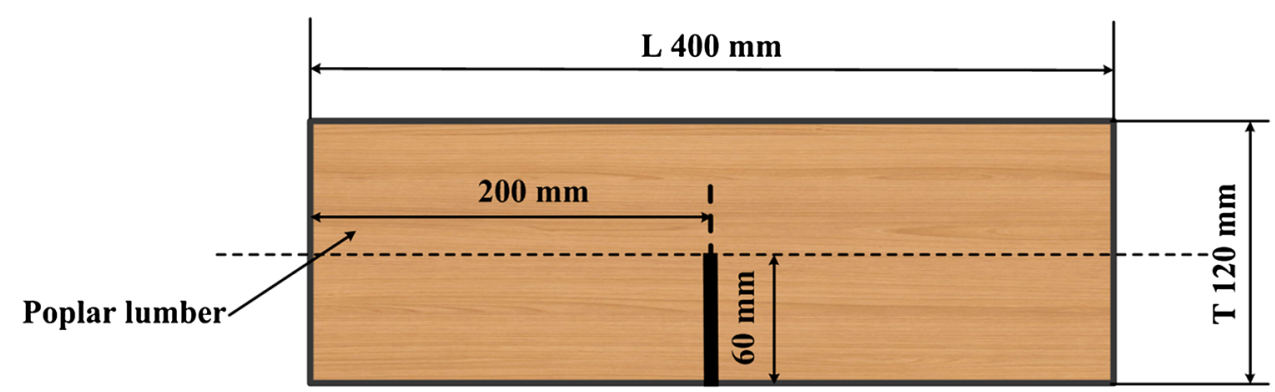

(b) Top view

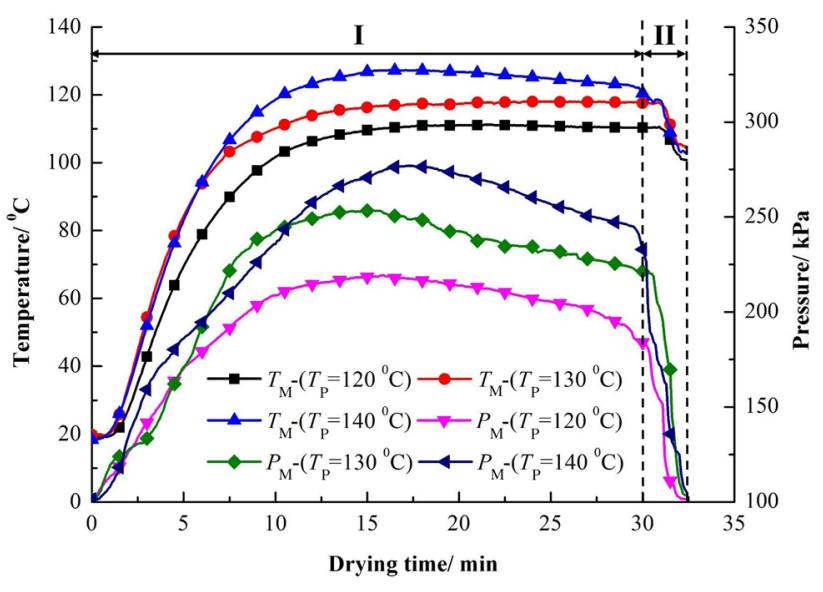

Fig. 5 Temperature and pressure curves in poplar lumber under different heating platens' temperatures (I: Closing period of heating platens; II: Opening period of heating platens)

observed during hot-press drying. When $T_{\mathrm{P}}$ was increased from 120 to $140{ }^{\circ} \mathrm{C}$, the maximum values of $T_{\mathrm{M}}$ at the center layer of lumber was increased from 111.2 to $127.3{ }^{\circ} \mathrm{C}$, time to the maximum values of $T_{\mathrm{M}}$ was decreased from 20.9 to $17.6 \mathrm{~min}$. When the heating platens closed, the heat transferred was absorbed by the water in the surface of lumber and resulted in the vaporisation of free water and the formation of evaporation front [24]. The evaporation front was gradually moved to the interior of lumber with the continuation of hot-press drying. Steam and water at the evaporation front was also moved to the center layer by the pressure difference between the evaporation front and center-layer in the closing period of heating platens, and large amount of heat energy was brought into center layer. This process increased $T_{\mathrm{M}}$ at the center layer. The heat was also transferred to the center layer of lumber by conduction from the heating platens [25]. Therefore, $T_{\mathrm{M}}$ at the center layer of lumber was rapidly increased and reached the maximum temperature. Furthermore, the temperature difference between the heating platens and lumber was increased with increase of $T_{\mathrm{P}}$ in the increasing stage of $T_{\mathrm{M}}$. The greater temperature difference between the heating platens and lumber resulted in the greater volume of heat conducted from the heating platens to lumber in unit time, so the larger amount of water vaporised at the evaporation front, the faster rising of $T_{\mathrm{M}}$ and the higher maximum temperature reached [26]. However, the $T_{\mathrm{M}}$ was sharply decreased to around $100{ }^{\circ} \mathrm{C}$ in short time with the opening of heating platens.

\section{Pressure behaviors}

Figure 5 also presents the pressure $\left(P_{\mathrm{M}}\right)$ curves in poplar lumber under different $T_{\mathrm{P}}$ values. The results showed that the $P_{\mathrm{M}}$ rapidly increased even before the water at the center layer evaporating. This phenomenon may be due to the moving of steam from the evaporation front to the interior of lumber and resulted in the increase of $P_{\mathrm{M}}$ in the closing period of heating platens. The obvious maximum pressure was also observed during hot-press drying. The maximum values of $P_{\mathrm{M}}$ increased from 219.4 to $276.9 \mathrm{kPa}$, and the corresponding $T_{\mathrm{M}}$ values increased from 110.2 to $127 .{ }^{\circ} \mathrm{C}$ with increase of $T_{\mathrm{P}}$ from 120 to $140{ }^{\circ} \mathrm{C}$. From the analysis of temperature behaviors at the center layer of lumber, the steam generated at the evaporation front was moved to the interior of lumber in the closing period of heating platens, 
which is driven by the pressure difference between the evaporation front and center layer, this resulted in the increasing of $P_{\mathrm{M}}$ at the center layer [27]. The great temperature difference between the heating platens and lumber resulted in the greater volume of heat transferred to inside lumber in unit time, the larger amount of water was vaporized at the evaporation front, the higher pressure difference was formed between the evaporation front and the center layer of lumber, the larger amount of steam was moved to the center layer of lumber from the evaporation front, and the greater the maximum $P_{\mathrm{M}}$ was reached [26].

A delay occurred between the maximum pressure and maximum temperature. The reason was that the steam generated at the evaporation front was immediately moved to the center layer and resulted in the increase of $P_{\mathrm{M}}$ at the center layer of lumber even before the water at the center-layer evaporating in the closing period of heating platens. However, the increase of $T_{\mathrm{M}}$ at the center layer was slow due to the conduction of heat from the heating platens to the center layer of lumber. With the continuation of hot-press drying, both $P_{\mathrm{M}}$ and $T_{\mathrm{M}}$ were increased to the maximum values.

The $P_{\mathrm{M}}$ was sharply decreased in the opening period of the heating platens, and the descending rate of pressure was increased with increasing $T_{\mathrm{P}}$. This is due to the moving out of steam from both surfaces of lumber in the closing period of heating platens. The pressure difference between the lumber and the atmospheric environment was increased with increasing $T_{\mathrm{P}}$ (Fig. 5), and this resulted in the higher moving rate of steam moved out from inside lumber [28], and cons versa, the higher moving rate of steam rapidly reduced $P_{\mathrm{M}}$. The pit membrane in the radial section of poplar lumber was also damaged due to the formation of pressure, and the gas permeability of poplar lumber was increased [29]. Furthermore, the lumber after higher $T_{\mathrm{P}}$ treatment was more permeable, and the steam was easier to move out from inside lumber. The pressure difference and increased permeability contributed to rapid reducing of $P_{\mathrm{M}}$.

\section{Moisture state changes in poplar lumber during hot-press drying}

Moisture state at the center layer of lumber was determined by the measured pressure $\left(P_{\mathrm{M}}\right.$ in Fig. 5) and the saturated vapor pressure $\left(P_{\mathrm{S}}\right)$ calculated with the measured temperature ( $T_{\mathrm{M}}$ in Fig. 5) during hot-press drying. The evaporation front was formed with the closing of heating platens and moved to the interior of lumber with the continuation of hot-press drying. Surface temperature of lumber was immediately increased to the boiling point of water at $100^{\circ} \mathrm{C}$ with the closing of heating platens and was maintained higher than $100^{\circ} \mathrm{C}$ throughout the whole hot-press drying process.

Moisture in wood was assumed to change into vapour once the temperature reaching $100{ }^{\circ} \mathrm{C}$ during hot-press drying from previous studies [20, 21]. Based on this assumption, the saturated vapour pressure $\left(P_{\mathrm{S}}\right)$ behaviors at the center layer of lumber can be divided into two stages (i.e. before and after $100{ }^{\circ} \mathrm{C}$ ) in accordance with the $T_{\mathrm{M}}$ at the center layer of lumber (Fig. 5). The 1st stage is for $T_{\mathrm{M}}$ at the center layer of lumber rapidly increased to $100{ }^{\circ} \mathrm{C}$. In this stage, moisture at the center layer of lumber was unsaturated water, i.e. liquid water, and $P_{\mathrm{S}}$ at the center layer of lumber was under atmospheric pressure. The 2 nd stage is for $T_{\mathrm{M}}$ at the center layer of lumber above $100{ }^{\circ} \mathrm{C}$. In this stage, the evaporation front was assumed to move to the center layer of lumber once $T_{\mathrm{M}}$ at the center layer of lumber above $100{ }^{\circ} \mathrm{C}$. $P_{\mathrm{S}}$ at the center layer of lumber was rapidly increased due to the violently vaporisation of free water inside the lumber [30]. $P_{\mathrm{S}}$ at the center layer of lumber in the 2 nd stage can be calculated using Eqs. 1 and 2 [31].

$P_{\mathrm{S}}=\frac{10^{f\left(T_{\mathrm{S}}\right)} \times P_{0}}{760}$

$$
\begin{aligned}
f\left(T_{\mathrm{S}}\right)= & 16.3737-\frac{2818.6}{\left(T_{\mathrm{S}}+273.15\right)} \\
& -1.6908 \times \log \left(T_{\mathrm{S}}+273.15\right) \\
& 5.7546 \times 10^{-3}\left(T_{\mathrm{S}}+273.15\right) \\
& +4.0073 \times 10^{-6}\left(T_{\mathrm{S}}+273.15\right)
\end{aligned}
$$

Where $P_{\mathrm{S}}$ is the saturated vapor pressure in $\mathrm{kPa}$; $P_{0}=101.325 \mathrm{kPa}$, is the standard atmospheric pressure; and $T_{\mathrm{S}}$ is the saturated temperature in ${ }^{\circ} \mathrm{C}$.

Comparison between $P_{\mathrm{M}}$ and $P_{\mathrm{S}}$ calculated with $T_{\mathrm{M}}\left(T_{\mathrm{S}}\right.$ $\left.=T_{\mathrm{M}}\right)$ at the center layer of lumber under different $T_{\mathrm{P}}$ values are displayed in Fig. 6. The MC distributions in poplar lumber before and after drying are listed in Table 1 . The

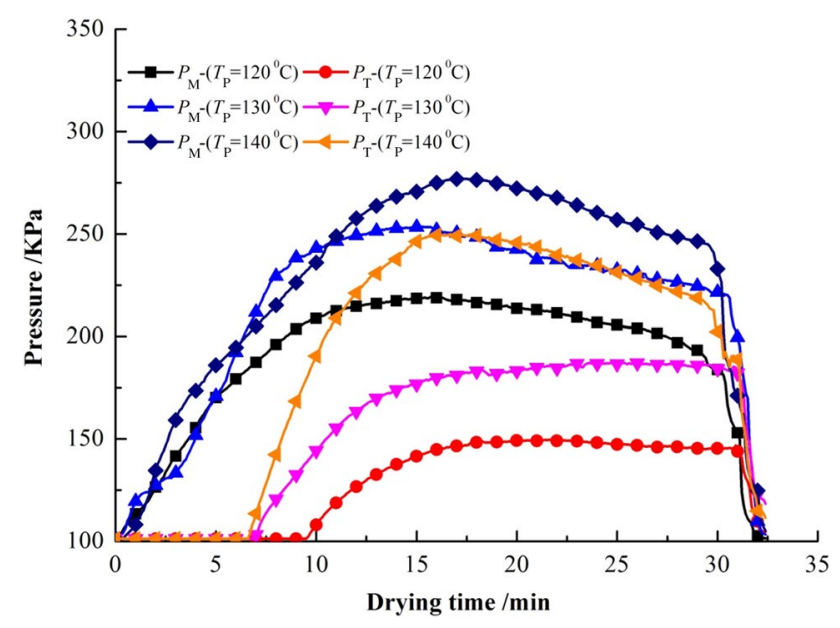

Fig. 6 Comparison between $P_{\mathrm{M}}$ and $P_{\mathrm{S}}$ in poplar lumber under different $T_{\mathrm{P}}$ values 
Table 1 MC distributions in poplar lumber before and after drying process

\begin{tabular}{lllll}
\hline Specimen no. & Initial MC $(\%)$ & Final MC $(\%)$ & $\begin{array}{l}\text { Final MC of surface } \\
\text { layer }(\%)\end{array}$ & $\begin{array}{l}\text { Final MC of } \\
\text { center layer } \\
(\%)\end{array}$ \\
\hline $120-1$ & $56.10 \pm 0.55$ & $40.78 \pm 0.50$ & $32.42 \pm 0.98$ & $57.88 \pm 2.60$ \\
$120-2$ & $59.38 \pm 1.28$ & $50.26 \pm 1.21$ & $31.90 \pm 1.00$ & $53.15 \pm 3.48$ \\
$120-3$ & $44.63 \pm 0.44$ & $34.69 \pm 0.41$ & $28.92 \pm 2.23$ & $42.06 \pm 1.93$ \\
120 -average & $53.37 \pm 7.75$ & $41.91 \pm 7.85$ & $31.08 \pm 1.89$ & $51.03 \pm 8.12$ \\
$130-1$ & $64.42 \pm 0.47$ & $49.41 \pm 0.42$ & $33.15 \pm 6.81$ & $70.42 \pm 1.20$ \\
$130-2$ & $54.87 \pm 0.82$ & $42.00 \pm 0.75$ & $21.95 \pm 2.52$ & $55.01 \pm 0.39$ \\
$130-3$ & $46.72 \pm 1.09$ & $37.56 \pm 1.03$ & $34.88 \pm 0.19$ & $46.68 \pm 2.36$ \\
130 -average & $55.34 \pm 8.86$ & $42.99 \pm 5.99$ & $29.99 \pm 7.02$ & $57.37 \pm 12.05$ \\
$140-1$ & $48.65 \pm 1.48$ & $33.17 \pm 1.32$ & $27.07 \pm 1.31$ & $46.75 \pm 3.69$ \\
$140-2$ & $57.30 \pm 4.27$ & $40.69 \pm 3.82$ & $29.88 \pm 4.29$ & $53.89 \pm 5.80$ \\
$140-3$ & $50.32 \pm 2.51$ & $40.18 \pm 2.34$ & $21.62 \pm 0.66$ & $52.16 \pm 5.82$ \\
140 -average & $52.09 \pm 4.59$ & $38.01 \pm 4.21$ & $26.19 \pm 4.20$ & $50.93 \pm 3.72$ \\
\hline
\end{tabular}

$M C$ moisture content of poplar lumber before and after drying process moisture state in poplar lumber during hot-press drying can be analysed according to the relationship between $P_{\mathrm{M}}$ and $P_{\mathrm{S}}$ in the lumber. In the 2 nd stage, $P_{\mathrm{M}}$ and $P_{\mathrm{S}}$ at the center layer of lumber were rapidly increased with the continuation of hot-press drying. However, $P_{\mathrm{M}}$ at the center layer of lumber was greater than $P_{\mathrm{S}}$ throughout the hot-press drying process. In this case, the $T_{\mathrm{M}}$ was lower than the boiling point of water under $P_{\mathrm{M}}$; hence, the moisture at the center layer of lumber was in liquid state, i.e. unsaturated water under overpressure condition. The reason was that the boiling point of water at the center layer of lumber was increased with increase of $P_{\mathrm{M}}$ [32]. $T_{\mathrm{M}}$ at the center layer of lumber was still lower than the corresponding boiling point of water under $P_{\mathrm{M}}$. Therefore, moisture in poplar lumber was not changed to steam even its temperature was higher than $100{ }^{\circ} \mathrm{C}$ under overpressure condition, which was above atmospheric pressure. The hypothesis of "the moisture in wood is changed to vapour once its temperature reaches $100{ }^{\circ} \mathrm{C}$ in hot-press drying process" from previous studies $[20,21]$ was proved to be unsuitable for the analysis of moisture state and the heat and mass transfer in wood during hot-press drying with MC above FSP. This conclusion was verified by MC data at the center layer of lumber in Table 1. The MC was higher than FSP and thus showed that liquid water existed in lumber.

In the opening period of heating platens, $P_{\mathrm{S}}$ at the center layer of lumber was changed to greater than $P_{\mathrm{M}}$ as depicted in Fig. 7. The partial enlarged details of $P_{\mathrm{M}}$ and $P_{\mathrm{S}}$ in opening period are shown in Fig. 7. The $P_{\mathrm{M}}$ inside lumber was decreased in the opening period of heating platens (Figs. 5, 6, 7). The boiling point of water was also decreased with the decreases in $P_{\mathrm{M}}$ at the center layer of lumber. Furthermore, the heat released from lumber was absorbed by unsaturated water in lumber. The $T_{\mathrm{M}}$ of unsaturated water at the center layer of lumber was higher than

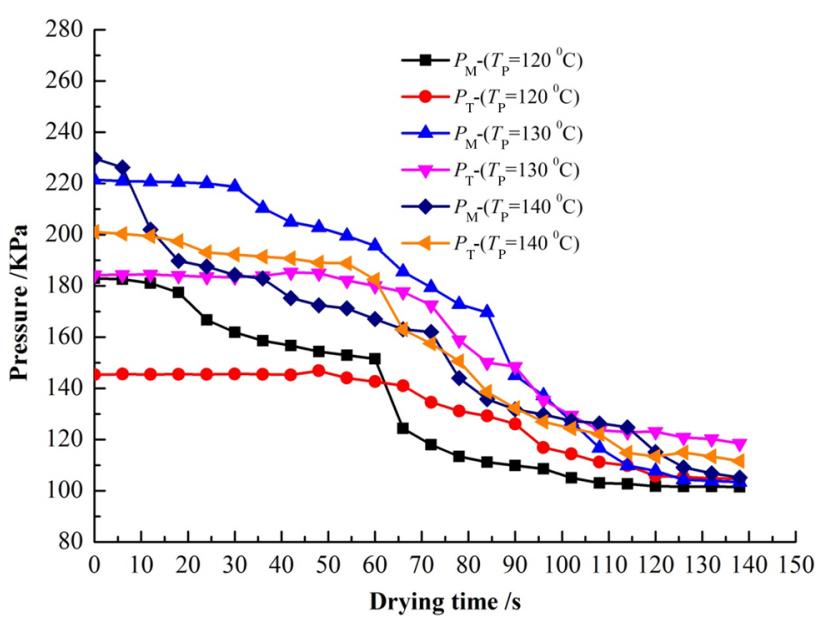

Fig. 7 Detail comparison between $P_{\mathrm{M}}$ and $P_{\mathrm{S}}$ in poplar lumber in the opening period of heating platens

the boiling point of water under related pressure with the opening of heating platens as shown in Fig. 7. This phenomenon resulted in the vaporisation of unsaturated water. Therefore, flashing occurred to the unsaturated water [33]. The steam, which is driven by the pressure gradient between the center-layer and atmospheric environment, moved out from inside lumber and consequently reduced the MC in lumber. It was found that decreased MC of poplar lumber was increased from 11.5 to $14.1 \%$ with the increase of $T_{\mathrm{P}}$ from 120 to $140{ }^{\circ} \mathrm{C}$ (Table 1 ). The greater the difference between $P_{\mathrm{M}}$ and $P_{\mathrm{S}}$, the greater the difference between the $T_{\mathrm{M}}$ of unsaturated water and the boiling point of water under $P_{\mathrm{M}}$, the stronger flashing of unsaturated water in lumber occurred, and the greater volume of steam moved out from inside lumber, the greater decrease 
in $\mathrm{MC}$ of lumber was expected as listed in Table 1. This process is the main moisture transfer mode in wood hotpress drying with MC above FSP.

\section{Conclusions}

Temperature and pressure were experimentally measured to study the effect of heating platens' temperature on the moisture state in poplar lumber with MC above FSP during hot-press drying. The following conclusions were drawn:

- The maximum temperature and pressure were observed at the center layer of poplar lumber during hot-press drying. As the increase of $T_{\mathrm{P}}$ from 120 to $140{ }^{\circ} \mathrm{C}$, the maximum values of temperature were increased from 111.2 to $127.3{ }^{\circ} \mathrm{C}$, whereas those of pressure were increased from 219.4 to $276.9 \mathrm{kPa}$. However, a delay occurred between the maximum values of pressure and temperature.

- Moisture at the center layer of poplar lumber was in liquid state, i.e. unsaturated water under overpressure condition with MC above FSP. Flashing was occurred to unsaturated water in poplar lumber at the moment of opening of heating platens, resulted in the decrease of MC. As the increase of $T_{\mathrm{P}}$ from 120 to $140{ }^{\circ} \mathrm{C}$, the decreased $\mathrm{MC}$ of poplar lumber was increased from 11.5 to $14.1 \%$. The greater the difference between the $P_{\mathrm{S}}$ and $P_{\mathrm{M}}$ at the center layer of poplar lumber, the stronger flashing of unsaturated water in lumber occurred, and the greater decline in MC of lumber in the opening period of heating platens. This process is the main moisture transfer mode in wood hot-press drying with MC above FSP.

Acknowledgements This work was financial supported by the National Forestry Industry Research Special Funds for Public Welfare Projects from State Forestry Administration of China (no. 201404502).

\section{References}

1. Tang YF, Hart CA, Simpson WT (1994) A numerical model for heat transfer and moisture evaporation processes in hot-press drying: an integral approach. Wood Fiber Sci 26(1):78-90

2. Guo YD, Li C (1988) Study on technique of lumber seasoning with pressure and heat (in Chinese). J Cent South For Coll $8(1): 40-47$

3. Jung HS, Lee NH, Yeo HM (1993) Press drying of planation softwood lumber (in Korean). J Korean Wood Sci Technol 21(3):61-66

4. Liu ZJ (2001) The high temperature thermal pressing study on the modification technique of pencil board (in Chinese). J Hebei For Orchard Res 16(3):236-239
5. Chen HY, Lang Q, Zhang H, Wu GF, Zheng X, Pu JW (2013) Study of chemical modification by impregnation of fresh Poplar Log and hot-pressed drying process. BioResources 8(3):3924-3933

6. Chai JB, Qian SJ (1997) A preliminary study on effects of pressdrying fast growing Chinese Fir upon dimensional stability (in Chinese). J Nanjing For Univ 21(4):106-109

7. Jiao DX, Jin CD, Zhang YF (2005) Study on the stress of lumber in the process of hot press drying (in Chinese). Wood Process Mach 6:23-25

8. Unsal O, Candan Z (2008) Moisture content, vertical density profile and Janka hardness of thermally compressed Pine wood panels as a function of press pressure and temperature. Dry Technol 26(9):1165-1169

9. Schrepfer V, Schweingruber FH (1998) Anatomical structure in reshaped press-dried wood. Holzforschung 52:615-622

10. Wang YH, Gu LB, Liu QM, Du GX (2009) Synthetic estimation of surface strengthening technique for fast-growing lumber from Pinus massoniana plantation (in Chinese). J Cent South Univ For Technol 29(5):105-109

11. Wu GF, Lang Q, Qu P, Jiang YF, Pu JW (2010) Effect of chemical modification and hot-press drying on Poplar wood. BioResources $5(4): 2581-2590$

12. Bronnhal G (1976) Fick's laws and bound-water diffusion. Wood Sci 8(3):153-156

13. Bronnhal G (1979) Sorption diffusion in wood. Wood Sci 12(1):3-13

14. Bramhall G (1995) Diffusion and the drying of wood. Wood Sci Technol 29(3):209-215

15. Miao P (200) Water movement and heat transfer during high temperature drying of Masson's Pine (in Chinese). Dissertation, Nanjing Forestry University, P.R. China

16. Li XJ, Zhang BG, Li WJ (2008) Microwave-Vacuum drying of wood: model formulation and verification. Dry Technol 26(11):1382-1387

17. Liu ZJ, Zhang BG (2006) Effect of internal pressure on moisture migration during wood microwave drying (in Chinese). China For Prod Ind 33(2): 17-19

18. Turner IW, Perré P (2004) Vacuum drying of wood with radiative heating: II. Comparison between theory and experiment. Aiche J 50(1):108-118

19. Perré P, Mosnier S, Turner IW (2004) Vacuum drying of wood with radiative heating: I. Experimental procedure. Aiche J 50(1):97-107

20. Wang YH, Gu LB, Liu QM, Du GX (2005) Mathematical models of moisture transfer in press drying of Pinus massoniana lumber (in Chinese). J Nanjing For Univ 32(2):71-75

21. Wang YH, Gu LB, Wang CG, Ke SH (2008) Regularity of heat transfer during press drying of Pinus massoniana lumber (in Chinese). J Nanjing For Univ 29(4):33-36

22. García PJ, Avramidis S, Lam F (2003) Horizontal gas pressure and temperature distribution responses to OSB flake alignment during hot-pressing. Holz Roh Werkst 61(6):425-431

23. GB/T 6494(2012) Drying quality of sawn timber (in Chinese). Chinese National Standardization Management Committee, Beijing, 5-6

24. Rofi MN, Kubota S, Kobori H, Kojima Y, Suzuki S (2016) Furnish type and mat density effects on temperature and steam pressure of wood-based panel during hot pressing. J Wood Sci 62:168-173

25. García PJ, Avramidis S, Lam F (2001) Internal temperature and pressure responses to flake alignment during hot-press drying. Holz Roh Werkst 9(6):425-431

26. Yan JL, Wang YQ (2014) Engineering Thermodynamics, 2nd edn. Electric Power Press, Beijing, pp 181-182 (in Chinese) 
27. Meyer N, Thoemen H (2007) Gas pressure measurements during continuous hot pressing of particleboard. Holz Roh Werkst 65:49-55

28. Rofi MN, Yamamoto N, Kojima Y, Suzuki S (2014) Effect of furnish on temperature and vapor pressure behavior in the center of mat panels during hot pressing. J Math Fund Sci 46(2):175-182

29. Peng YQ (2013) Effects of pre-steaming on the characteristics and Vacuum drying rate of Poplar. Dissertation, Beijing Forestry University, P. R. China

30. Haque MN (2007) Analysis of heat and mass transfer during high temperature drying of Pinus radiate. Dry Technol 25:379-389
31. Pang S (1997) Some considerations in simulation of superheated vapor drying of softwood lumber. Dry Technol 15(2):651-670

32. Liu H, Xiao H (2011) Study on inverse formula of steam saturation temperature (in Chinese). Inner Mongulia Petrochem Ind 37(9):33-34

33. Hu HB (2004) Application of flashing technology to the power generation by waste heat (in Chinese). Power Syst Eng 5:53-54 